\title{
CORRECTIONS
}

\section{Saturated fat is not the major issue}

This Observations article (BMJ 2013;347:f6340, doi:10.1136/ bmj.f6340) by Aseem Malhotra stated that a recent "real world" study of 150000 patients who were taking statins showed "unacceptable" side effects-including myalgia, gastrointestinal upset, sleep and memory disturbance, and erectile dysfunction-in $20 \%$ of participants. The author withdraws this statement. Although it was based on statements in the referenced observational study by Zhang and colleagues that "the rate of reported statin-related events to statins was nearly $18 \%, " 1$ the article did not reflect necessary caveats and did not take sufficient account of the uncontrolled nature of the study.

1 Zhang H, Plutzky J, Skentzos S, Morrison F, Mar P, Shubina M, et al. Discontinuation of statins in routine care settings. Ann Intern Med 2013;158:526-34.

Cite this as: BMJ 2014;348:g3332

(๑) BMJ Publishing Group Ltd 2014 